\title{
ambient SCIENCE

\section{Prenatal and Postnatal Echocardiography in Euploid Fetuses with Increased Nuchal Translucency}

\author{
Kobra Shojaei ${ }^{1}$, Razie Amirpour ${ }^{1 *}$, Mojgan \\ Barati', Abdolrahman Emami-Moghaddam ${ }^{2}$ \\ ${ }^{1}$ Fertility Infertility and Perinatology Research Center, \\ Department of obstetrics \& gynecology, Ahvaz Jundishapur \\ University of Medical Sciences, Ahvaz, Iran \\ ${ }^{2}$ Cardiac pediatric, Jundishapur University of Medical Sciences, \\ Ahvaz, Iran. \\ Study Area:Ahvaz, Iran \\ Coordinates: 31 ${ }^{\circ} 19^{\prime} 13^{\prime \prime N}$; $48^{\circ} 40^{\prime} 09^{\prime E}$
}

Keywords: Fetal heartabnormality, NT

The study was approved by the ethics committee of Ahvaz university of medical sciences (Moral code: IR.AJUMS.REC. 1396.448).

\begin{abstract}
Using targeted fetal echocardiography in the middle of the pregnancy period can detect most of the major cardiac defects and large vessels. The present study aims to evaluate the echocardiography for both before and after birth in fetuses with elevated NT and normal karyotype. This Retrospective study was conducted to evaluate the chromosome implication of the euploid fetuses with elevated NT. The present study included live fetuses at the gestational age of 11-14 weeks and NT > 95 percentile (or more than $3 \mathrm{~mm}$ ). All of the euploid fetuses with increased NT anomaly were followed using a follow-up scan at the 18$22^{\text {th }}$ pregnancy week and fetal echocardiography at the 16$19^{\text {th }}$ pregnancy week. Physical examinations and postnatal echocardiography were performed to conf irm the diagnosis of congenital heart disease in live births. In $73.68 \%$ of the fetuses, the congenital heart defect was diagnosed before birth and that confirmed after birth too. The strongest correlation was observed between elevated NT and prenatal diagnosis of a congenital heart defect in the thickness of 3.4$5.2 \mathrm{~mm}$. The highest percentage of correct diagnosis of fetal congenital heart defect occurred in mothers with a BMI of more than 24.99 and age of 19 to 25 years old. The rate of increased NT went up in younger mothers and also who had a lower BMI. A variety of congenital heart defects associated with increased NT in the first trimester of pregnancy. The possibility of a correct diagnosis of fetal heart abnormalities decreased with the increase of BMI. The likelihood of a correct diagnosis of fetal heart abnormalities increased in younger mother. It is possible to evaluate the likelihood of fetal heart defects by measuring NT in the 11 th to $13^{\text {th }}$ pregnancy week and considering basic risk factors.
\end{abstract}

approved as a sensitive parameter for the screening of chromosomal and heart defects in both chromosomally normal and abnormal fetuses (Orosz et al., 2009; Galindo et al., 2003). Several studies reported that euploid fetus with elevated NT is at a higher risk for a wide range of fetal structural defects, in particular, congenital heart defects as well as specific genetic syndromes (Orosz et al., 2009; Galindo et al., 2003; Barker Clur, 2010; Bilardo et al., 1998, 2007; Clus et al., 2008; Tahmasebpour et al., 2012; Souka et al., 2001, 2005; Lopes et al., 2003).

The exact pathological reason of elevated NT is still unknown. Probable etiologic factors are cardiac Translucency (NT) thickness measurement has been 
RESEARCH ARTICLE

dysfunction, venous congestion in the head and neck, abnormal or delayed evolution of the lymphatic system, modified combination of the extracellular matrix, lymphatic drainage failure, fetal anemia or hypoproteinemia, congenital infections, musculoskeletal abnormalities, and hormonal disorders (Orosz et al., 2009; Saldanha et al., 2009; Tahmasebpour et al., 2012). Since the majority of fetuses with elevated NT and normal karyotype suffered from the congenital heart defect, a new high-risk group requiring fetal echocardiography has been defined (Lopes et al., 2003). Using targeted fetal echocardiography in the middle of the pregnancy period, one can detect most of the major cardiac defects and large vessels. The prevalence of fetal abnormalities and undesirable pregnancy outcomes exponentially increase with NT thickness, in particular, when its thickness reaches $3.5 \mathrm{~mm}$ (Saldanha et al., 2009). Despite conducting many studies in this area, there is still uncertainty and concern about the implication of fetuses with elevated NT (Tahmasebpour et al., 2012). The present study aims to evaluate the echocardiography for both before and after birth in fetuses with elevated NT and normal karyotype..

\section{Methodology:}

This Retrospective study was conducted between the year 2014 to 2015 to evaluate the chromosome implication of the euploid fetuses with elevated NT. In this study, the information of the pregnant women fetuses referred to the Narges laboratory of Ahvaz for the first-trimester screening was evaluated. The present samples included live fetuses at the gestational age of 11-14 weeks and NT > 95 percentile (or more than $3 \mathrm{~mm}$ ) screened and recorded in Narges laboratory of Ahvaz. Three methods were used to analyze the karyotypes for fetuses with increased NT to determine chromosomal or genetic disorders including i) amniocentesis, ii) cell free DNA, and iii) chorionic villus sampling (CVS). All of the euploid fetuses with increased NT anomaly were followed using a follow-up scan at the 18$22^{\text {th }}$ pregnancy week and fetal echocardiography at the 16$19^{\text {th }}$ pregnancy week. Physical examinations and postnatal echocardiography were done to conf irm the diagnosis of congenital heart disease in live births. Moreover, all children were examined by a neonatologist at the time of birth and the pieces of information were recorded according to the checklist. All statistical analyses were performed using IBM SPSS softwareversion 21.

\section{Results:}

In the present study, the records of 34 women aging between 20 and 38 years old were analyzed. Out of 34 pregnant women, four cases had twin pregnancies; therefore total 38 fetuses were considered for examination. Demographic pieces of information of the patients are in Table-1.
Ambient Science, 2018: Vol. 05(Sp1); 90-92 DOI:10.21276/ambi.2018.05.sp1.ra09

Table 1. The demographic information of patients

\begin{tabular}{ll}
\hline Variables & Mean \pm SD \\
\hline Age (year) & $30.24 \pm 4.564$ \\
Gestational age (week) & $20.95 \pm 3.304$ \\
BMI & $27.45 \pm 3.168$ \\
\hline
\end{tabular}

Three methods were used to analyze the karyotypes for fetuses with increased NT including amniocentesis, CVS, and cell free DNA. However, amniocentesis method was used more than the other methods in karyotype analysis (Table-2).

Table 2. Karyotype analysis methods

\begin{tabular}{lll}
\hline Method & $\mathrm{n}$ & $\%$ \\
\hline Cell Free DNA & 13 & 34.21 \\
Amniocentesis & 23 & 60.53 \\
CVS & 2 & 5.26 \\
\hline
\end{tabular}

The effect of NT rate in the first trimester on pre or postnatal echocardiography findings was also evaluated. According to the results, $26.32 \%$ of prenatal congenital heart defect diagnosis was confirmed after the birth. Table-3 reveals the results of comparing the echocardiography before and after birth and determining the relationship between NT rate and the increase of congenital heart abnormalities.

Table 3.Comparison of the echocardiography findings for both before and after birth according to the NT

Echocardiography

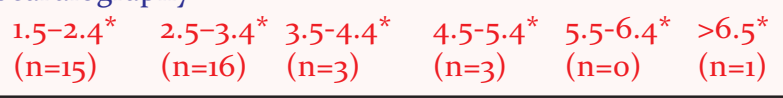

Echocardiography Normal (before \& after birth) $(\mathrm{p}<\mathbf{0 . 0 2 7})$

$\begin{array}{lllllll}\mathrm{n} & 5 & 3 & 1 & 2 & - & \mathrm{o}\end{array}$

$\% \quad 45.45 \% \quad 27.27 \% \quad 9.09 \% \quad 18.18 \%-\quad 0 \%$

Echocardiography Abnormal (before \& after birth) ( $\mathbf{p}<\mathbf{0 . 0 4})$

$\begin{array}{lllllll}\text { n } & 3 & 6 & 0 & 1 & - & 0\end{array}$

$\% \quad 30 \% \quad 60 \% \quad 10 \%$

Normal (before birth)/ Abnormal (after birth) $(\mathrm{p} \geq 0.287)$

$\begin{array}{lllllll}\text { n } & 2 & 1 & 0 & 0 & - & 0\end{array}$

$\% \quad 66.67 \% \quad 33.33 \% \quad 10 \%$

Abnormal (before birth)/ Normal (after birth) ( $p<0.007)$

$\begin{array}{lllllll}\text { n } & 5 & 6 & 2 & 0 & - & 1\end{array}$

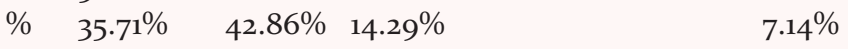

As shown in Table-3, the strongest correlation was observed between elevated NT and pre-natal diagnosed of congenital heart defect with the thickness of 3.4-5.2 mm.

It should be noted that since only one fetus was with the thickness of more than $6.5 \mathrm{~mm}$, there is a need for examination in more fetuses. Ectopia Cordis Anomalies were also studied after birth in all fetuses and all of which were reported as normal.

\section{Discussion:}

Our results evidenced a strong correlation between the increase of NT and heart abnormalities which can be seen 
in fetuses with normal and abnormal chromosomes (Hyett et al., 1997; 1999; ). Our results also revealed that $26.32 \%$ of prenatal congenital heart defect diagnosis was conf irmed after the birth. According to the results, the strongest correlation $(60 \%)$ was observed between the diagnosis of a prenatal congenital heart defect and the thickness of 2.5 to $3.4 \mathrm{~mm}$. The present results were consistent with the findings of Orosz et al. (2009), in which the prevalence of heart defects increased with NT enhancement. In line with our results, Saldanha et al. (2009) reported that the prenatal heart defects and postnatal abnormalities are related to the NT thickness. Additionally, the results strengthened Bilardo et al. (1998)'s findings, in which there was a strong correlation between increased NT measurements and congenital heart anomalies.

Barker et al. (2007) reported that only $4.9 \%$ of fetuses with increased NT and normal karyotype suffered from congenital heart defect which was considerably lower than our results. Inconsistent with our results, Maymon et al. (2000) reported a very low prevalence of abnormalities in fetuses with increased NT. The present findings found no postnatal ectopiacordis anomalies which cannot confirm Orosz et al. (2009) in which other anomalies were increased with the enhancement of NT. Furthermore, Bilardo et al. (2007) demonstrated that only $20 \%$ of fetuses with increased NT suffered from adverse pregnancy outcomes and postnatal abnormalities.

Conclusively, a variety of congenital heart defects associated with increased NT in the first trimester of pregnancy. According to the results, it is possible to evaluate the likelihood of fetal heart defects by measuring NT in the 11th to 13th pregnancy week and considering basic risk factors.

Acknowledgment:

This study was approved in Ahvaz Jundishapur University of Medical Sciences (AJUMS). The study was financially supported by AJUMS (Grant.No.: FIRC-9607).

\section{References:}

Barker Clur S-A. (2010): Fetal heart and increased nuchal translucency: anatomical, pathophysiological, diagnostic and clinical aspects. $\mathrm{PhD}$ thesis. University of Amsterdam.

Becker, R. \& Wegner, R.D. (2006): Detailed screening for fetal anomalies and cardiac defects at the 1113-week scan. Ultrasound Obstet. Gynecol., 27(6):613-618.

Bilardo, C., Müller, M., Pajkrt, E., Clur, S., Van Zalen, M. \& Bijlsma, E. (2007): Increased nuchal translucency thickness and normal karyotype: time for parental reassurance. Ultrasound Obstet. Gynecol., 30(1):11-18.
Bilardo, C., Pajkrt, E., De Graaf, I., Mol, B. \& Bleker, O. (1998): Outcome of fetuses with enlarged nuchal translucency and normal karyotype. Ultrasound Obstet. Gynecol., 11(6):401406.

Clur, S., Mathijssen, I., Pajkrt, E., Cook, A., Laurini, R., Ottenkamp, J. \& Bilardo, C.M. (2008): Structural heart defects associated with an increased nuchal translucency: 9 years experience in a referral centre. Prenat. Diagn., 28(4):347-354.

Galindo, A., Comas, C., Martinez, J., Gutierrez-Larraya, F., Carrera, J., Puerto B, Borrell, A., Mortera, C. \& de la Fuente, P. (2003): Cardiac defects in chromosomally normal fetuses with increased nuchal translucency at 1014 weeks of gestation. $L$ Maternal-Fetal Neonatal Med., 13(3):163-170.

Haak, M.C. \& van Vugt, J.M. (2003): Echocardiography in early pregnancy.JUltrasound Med. . 22(3):271-280.

Hyett, J., Moscoso, G. \& Nicolaides, K. (1997): Abnormalities of the heart and great arteries in first trimester chromosomally abnormal fetuses. Am. J. Med. Gen... 69(2):207-216.

Hyett, J., Perdu, M., Sharland, G., Snijders, R. \& Nicolaides, K.H. (1999): Using fetal nuchal translucency to screen for major congenital cardiac defects at 10-14 weeks of gestation: population based cohort study. $\underline{B M I} \cdot 318(7176): 81-85$.

Lopes, L., Brizot, M., Lopes, M., Ayello, V., Schultz, R. \& Zugaib, M. (2003): Structural and functional cardiac abnormalities identified prior to 16 weeks' gestation in fetuses with increased nuchal translucency. Ultrasound Obstet. Gynecol., 22(5):470-478.

Maymon, R., Jauniaux, E., Cohen, O., Dreazen, E., Weinraub, Z. \& Herman, A. (200o): Pregnancy outcome and infant follow-up of fetuses with abnormally increased first trimester nuchal translucency. Human Reprod., 15(9):2023-2027.

Orosz, L., Lukacs, J., Szabó, M., Kovacs, T., Zsupan, I. \& Orosz, G. (2009): Long-term outcome of pregnancies with increased nuchal translucency and normal karyotype. Donald School J. Ultrasound Obstet. Gynecol., 2009;3(3):83-89.

Saldanha, F.A.T., Brizot, M.D.L., Moraes, E.A.D., Lopes, L.M. \& Zugaib, M. (2009): Increased fetal nuchal translucency thickness and normal karyotype: prenatal and postnatal follow-up. Revista Assoc. Médica Brasileira. 55(5):575-580.

Souka, A.P., Krampl, E., Bakalis, S., Heath, V. \& Nicolaides, K.H. (2001): Outcome of pregnancy in chromosomally normal fetuses with increased nuchal translucency in the first trimester. Ultrasound Obstet. Gynecol., 18(1):9-17.

Souka, A.P., von Kaisenberg, C.S., Hyett, J.A., Sonek, J.D. \& Nicolaides, K.H. (2005): Increased nuchal translucency with normal karyotype. Am.J. Obs. Gynecol., 192(4):1005-1021.

Tahmasebpour, A., Rafiee, N.B., Ghaffari, S. \& Jamal, A. (2012): Increased nuchal translucency and pregnancy outcome.Iran. J. Pub. Health, 41(11):92-97 